\title{
Microstructure evolution and strengthening mechanisms of Fe-23Mn-0.3C-1.5Al TWIP steel during cold rolling
}

\author{
Pavel Kusakin $^{\mathrm{a}, *}$, Andrey Belyakov ${ }^{\mathrm{a}}$, Christian Haase ${ }^{\mathrm{b}}$, Rustam Kaibyshev ${ }^{\mathrm{a}}$, \\ Dmitri A. Molodov ${ }^{\mathrm{b}}$

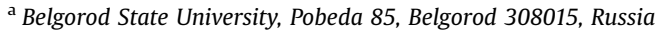 \\ ${ }^{\mathrm{b}}$ Institute of Physical Metallurgy and Metal Physics, RWTH Aachen University, 52056 Aachen, Germany
}

\section{A R T I C L E I N F O}

\section{Article history:}

Received 14 May 2014

Received in revised form

30 July 2014

Accepted 18 August 2014

Available online 28 August 2014

\section{Keywords:}

TWIP-steel

Electron microscopy

Microstructure

Fractography

Hardening

Mechanical characterization

\begin{abstract}
A B S T R A C T
The effect of cold rolling on the microstructure evolution and mechanical properties of Fe-23Mn-0.3C1.5Al twinning-induced plasticity (TWIP) steel was studied. The extensive mechanical twinning subdivides the initial grains into nanoscale twin lamellas. In addition, the formation of deformation micro bands at $\varepsilon>40 \%$ induces the formation of nanostructured bands of localized shear. It is demonstrated that the mechanical twinning is notably important for dislocation storage within the matrix, as the twin boundaries act as equally effective obstacles to dislocation glide as conventional high-angle grain boundaries. However, the contribution of the grain size strengthening to the overall yield stress (YS) is much smaller than that of the deformation strengthening, which plays a major role in the superior work-hardening behavior of TWIP steels. A very high dislocation density of $\sim 2 \times 10^{15} \mathrm{~m}^{-2}$ is achieved after plastic deformation with moderate strains. The superposition of deformation strengthening and grain boundary strengthening leads to an increase in the YS from $235 \mathrm{MPa}$ in the initial state to $1400 \mathrm{MPa}$ after $80 \%$ rolling.
\end{abstract}

(c) 2014 Elsevier B.V. All rights reserved.

\section{Introduction}

There is a considerable demand for advanced high-strength steels with high formability for structural parts in automobile bodies [1]. Austenitic steels with high Mn content exhibit the most attractive combination of tensile strength and superior ductility due to their extraordinary strain-hardening rate, which is interpreted in terms of twinning-induced plasticity (TWIP) [2-6]. It is known that in face-centered cubic (fcc) metals with low stacking fault energies (SFEs),extensive deformation twinning results in the formation of deformation twins with a plate-like shape as well as nanometer spacing and thickness [2,7-9]. The twin boundaries, which are special (low $-\Sigma$ coincidence site lattice) high-angle boundaries [7] and contain a high density of sessile dislocations [8], act as equally effective obstacles to dislocation gliding as conventional grain boundaries in polycrystalline austenitic steels [10]. The subdivision of initial grains into lamellas with thicknesses ranging from 10 to $40 \mathrm{~nm}[2-6,8]$ leads to a significant decrease in the effective grain size and, therefore, results in

\footnotetext{
*Corresponding author. Tel.: +7 4722 585409; fax: +7 4722585406.

E-mail addresses: kusakin@bsu.edu.ru (P. Kusakin), belyakov@bsu.edu.ru (A. Belyakov), haase@imm.rwth-aachen.de (C. Haase), rustam_kaibyshev@bsu.edu.ru (R. Kaibyshev), molodov@imm.rwth-aachen.de (D.A. Molodov).
}

remarkable strengthening in accordance with the Hall-Petch relationship [11-13]:

$\sigma_{0.2}=\sigma_{0}+K_{\mathrm{H}} d^{-0.5}$

where $\sigma_{0.2}$ is the offset yield strength; $d$ is the effective grain size, which is the distance between barriers to dislocation glide and can be estimated to be twice the width of lamellae [14]; $\sigma_{0}$ is the friction stress; and $K_{\mathrm{H}}$ is the Hall-Petch coefficient. A "dynamic Hall-Petch effect" [2-6,8] attributed to the reinforcement of austenite by deformation twins was exploited to explain the extraordinary ductility of the TWIP steels $[9,15]$. However, it is apparent that this interpretation of the very high strain-hardening rate of TWIP steels in terms of the dynamic Hall-Petch effect is oversimplified and open to debate.

Generally, an increase in the yield strength of TWIP steels by cold working is associated with grain boundary strengthening, strain hardening and dynamic strain aging (DSA) [2-6,8,9,15-17]. In high-Mn TWIP-steels, DSA is a type of solid solution strengthening attributed to the formation of interstitial $\mathrm{C}$ - substitutional Mn dipoles interacting strongly with dislocations or stacking faults. In turn, grain boundary strengthening may be caused by different mechanisms $[13,18]$ strongly related to dislocation strengthening. Grain boundary strengthening due to mechanical twinning is associated with the accumulation of lattice dislocations in pile-ups to attain critical stress concentration, which is 
necessary to induce the operation of the dislocation sources in neighboring grains or the boundary dislocation sources $[13,18]$. In the original Hall-Petch hypothesis, the dislocation pile-ups form at the grain boundary $[11-13,18]$. The stress concentration at the pile-up fronts, which is directly proportional to the number of piled-up dislocations and dislocation storage within the crystallites outlined by twin boundaries, increases the yield stress (YS) with decreasing grain size. It is worth noting that materials with nanocrystalline structures may exhibit a deviation from the HallPetch relationship [19]. The Hall-Petch relationship was shown to be valid for lamellar structures with an interboundary spacing of $\sim 20 \mathrm{~nm}$ in which the pile-ups involve approximately 10 dislocations within a single lamella [14] and the length of the pile-up is equal to the spacing between twin boundaries [15]. However, the $K_{\mathrm{H}}$ value tends to decrease with decreasing interlamellar spacing, which can further lead to the so-called inverse Hall-Petch effect when the effective grain size falls below $\sim 10 \mathrm{~nm}[20,21]$.

The dislocation strengthening provides a major contribution to the overall strength of TWIP steels due to the storage of a very high dislocation density of $\rho \sim 10^{15} \mathrm{~m}^{-2}$ during plastic deformation $[2,22]$. In general, the dislocation density in TWIP steels is one order of magnitude higher than that in other fcc metals deformed to the same strain [8]. The extensive mechanical twinning subdivides the initial grains into separate crystallites bounded by twin boundaries, which reduces the mean free path of lattice dislocation, leading to extraordinary accumulation of lattice dislocations $[2,5,8,22,23]$. In addition, the DSA and the slip-twin interactions hinder dynamic recovery [8]. The slip-slip and slip-twin interactions enable the formation of numerous sessile dislocations, which act as effective barriers for mobile dislocations and thus increase dislocation hardening significantly $[5,6,22,23]$. Therefore, the extensive mechanical twinning strongly promotes the dislocation hardening through a progressive reduction of the mean free path of dislocations. This builds up the dense dislocation pile-ups and results in high long-range internal stresses [6], which act as back stresses [9].

The main aim of the present work was to clarify the superior strain-hardening capacity of Fe-23Mn-0.3C-1.5Al steel, which is a typical representative of the advanced high-Mn TWIP steels. To this end, the microstructure evolution during cold rolling and the corresponding mechanical properties were studied. This steel contains aluminum, which usually fully or partially suppresses DSA at room temperature $[17,24]$. Therefore, only two strengthening mechanisms, grain boundary strengthening and dislocation strengthening, may substantially contribute to the overall strain hardening of this steel. Additionally, the aluminum additives increase the twin thickness and suppress the secondary twinning at high strains $[4,6]$. The twin thickness of approximately $30 \mathrm{~nm}$ is well above the lower bound of the interboundary spacing that allows the bowing of a dislocation loop across the twin. Therefore, grain boundary strengthening is operative due to the increased stress needed for dislocation propagation across the lamellar section [14].

The major shortcoming of high-Mn austenitic steels is their relatively low YS, which is associated with the recrystallized microstructure that evolves after conventional thermo-mechanical processing (TMP) $[25,26]$. Generally, the YS can be increased by an appropriate cold working at the expense of ductility [25]. The development of technological routes involving cold working for

\section{Table 1}

Chemical composition of the investigated steel.

\begin{tabular}{lllllllll}
\hline Element & $\mathrm{C}$ & $\mathrm{Mn}$ & $\mathrm{Al}$ & $\mathrm{Si}$ & $\mathrm{Cr}$ & $\mathrm{S}$ & $\mathrm{P}$ & $\mathrm{Fe}$ \\
\hline [Wt\%] & 0.304 & 23.1 & 1.5 & 0.09 & 0.08 & 0.006 & 0.017 & Bal. \\
\hline
\end{tabular}

producing TWIP-steels with the beneficial combination of strength and ductility requires detailed investigation of the mechanisms of microstructure evolution during deformation and careful analysis of the strain-hardening mechanisms. Recent studies on TWIP steels with various manganese contents have revealed the common sequence of structural changes during cold rolling $[5,25,27,28]$. Following a rapid increase in the dislocation density at an early deformation, the deformation twinning progressively develops throughout the deformation microstructures at low to medium strains, whereas shear banding occurs at rather high strains. The number of shear bands and their size gradually increase with straining. The formation of shear bands at high strains is associated with the rearrangement of twin lamellae along the rolling plane. In the present work, the effect of strain on the deformation microstructure evolution and the mechanical behavior of Fe-23Mn-0.3C$1.5 \mathrm{Al}$ steel was addressed.

\section{Experimental}

The chemical composition of the investigated steel is given in Table 1 . The steel was melted in an air conduction furnace and cast into a $30-\mathrm{kg}$ ingot ( $140 \mathrm{~mm}$ in height), followed by homogenization heat treatment at $1150{ }^{\circ} \mathrm{C}$ for $5 \mathrm{~h}$. The ingot was forged at $1150{ }^{\circ} \mathrm{C}$ to a height of $50 \mathrm{~mm}$ and solution treated at $1150{ }^{\circ} \mathrm{C}$ for $5 \mathrm{~h}$, followed by air cooling. The $50-\mathrm{mm}$-thick slab was hot rolled at an initial temperature of $1150{ }^{\circ} \mathrm{C}$ to a thickness of $10 \mathrm{~mm}$ and then annealed at the same temperature for $1 \mathrm{~h}$. The obtained plate was cold rolled to final thicknesses of $8,6,4$ and $2 \mathrm{~mm}$ with rolling reductions of $20,40,60$ and $80 \%$, respectively. The rolling direction (RD) was the same under hot and cold rolling.

The structural investigations were carried out on the longitudinal section (RD: normal direction (ND)) of the rolled samples. The sheets were ground on 1200, 2400 and 4000 grit SiC paper, mechanically polished using $3-$ and $1-\mu \mathrm{m}$ diamond suspensions, and electropolished for $20 \mathrm{~s}$ at $22 \mathrm{~V}$ and $20^{\circ} \mathrm{C}$. The electrolyte contained $700 \mathrm{ml}$ ethanol $\left(\mathrm{C}_{2} \mathrm{H}_{5} \mathrm{OH}\right), 100 \mathrm{ml}$ butyl glycol $\left(\mathrm{C}_{6} \mathrm{H}_{14} \mathrm{O}_{2}\right)$ and $78 \mathrm{ml}$ perchloric acid $(60 \%)\left(\mathrm{HClO}_{4}\right)$. Microstructure analysis using electron backscatter diffraction (EBSD) was performed in a LEO 1530 field emission gun electron microscope equipped with an EBSD detector and operated at a $20-\mathrm{kV}$ accelerating voltage. A step size of $0.8 \mu \mathrm{m}$ was used. For optical microscopy, the specimens were etched at room temperature using an etching solution consisting of $2 \mathrm{~g}$ potassium disulfide $\left(\mathrm{K}_{2} \mathrm{~S}_{2} \mathrm{O}_{5}\right)$ and $100 \mathrm{ml}$ cold saturated Klemm's I solution $\left(\mathrm{Na}_{2} \mathrm{~S}_{2} \mathrm{O}_{3}+5 \mathrm{H}_{2} \mathrm{O}\right)$. For microstructural characterization by transmission electron microscopy (TEM), thin foils of 3-mm diameter were cutout parallel to the RDND plane and ground to a $0.1-\mathrm{mm}$ thickness before being polished using a double-jet TENUPOL-5 electrolytic polisher in a mixed solution of $90 \%$ acetic acid and $10 \%$ perchloric acid at room temperature and an applied potential of $20 \mathrm{~V}$. The foils were examined using a JEOL JEM-2100 TEM operated at an acceleration voltage of $200 \mathrm{kV}$. The distance between deformation twins was measured by the mean linear intercept method, in which the direction of the measuring line was normal to the twin boundaries. The volume fraction of shear bands was calculated by the systematic point count method using a square grid. A least 10 TEM micrographs per specimen were used to obtain the relevant statistics. Average values of the crystallite size $d^{\prime}$ and microstrains $\left\langle\varepsilon_{50}^{2}\right\rangle$ were estimated on the basis of the Williamson-Hall plot [29] given by Eq. (2):

$\frac{\beta_{s} \cos \Theta}{\lambda}=\frac{2\left\langle\varepsilon_{50}^{2}\right\rangle \sin \Theta}{\lambda}+\frac{K}{d^{\prime}}$

where $\Theta$ is Bragg angle, $K$ is the Scherrer constant and $\beta_{s}$ is the full width at the half maximum height (FWHM) of $K_{\alpha 1}$ line with the 
correction of instrumental line broadening. In this study, the FWHM values were measured for $\gamma$-Fe (111) and (222) reflections. The instrumental line broadening was obtained from the FWHM value $\left(\beta_{r}\right)$ of $K_{\alpha 1}$ line of an annealed silicon powder and removed from measured FWHM value $\left(\beta_{m}\right)$ of $K_{\alpha 1}$ line of TWIP-steel on the following Eq. [30]:

$\beta_{s}^{2}=\beta_{m}^{2}-\beta_{r}^{2}$

The dislocation density was evaluated by X-ray diffraction profile analysis using an ARL-Xtra diffractometer operated at $45 \mathrm{kV}$ and $35 \mathrm{~mA}$ with $\mathrm{Cu} \mathrm{K} \alpha$ radiation. The value of the dislocation density $\rho$ was calculated from the average values of the crystallite size $D$ and microstrain $\left\langle\varepsilon^{2}\right\rangle$ by the following relationship [31]:

$\rho=\frac{3 \sqrt{2 \pi}<\varepsilon_{50}^{2}>}{\mathrm{D} b}$

where $b$ is the Burgers vector $\left(b=2.5 \times 10^{-10} \mathrm{~m}\right)$.

The tensile tests were carried out at room temperature using an Instron 5882 testing machine. Tensile specimens with a gauge length of $16 \mathrm{~mm}$ and cross section of $1.5 \mathrm{~mm} \times 3 \mathrm{~mm}$ were cut out with the tensile axis parallel to the rolling axis. The samples were

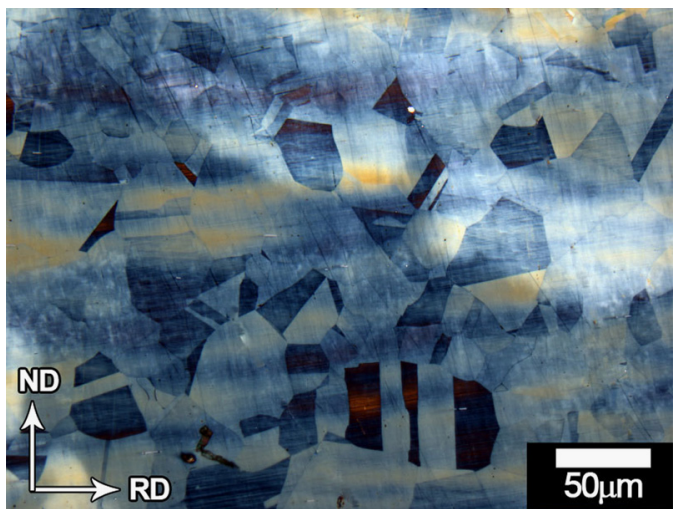

Fig. 1. Initial microstructure of the investigated Fe-23Mn- $0.3 \mathrm{C}-1.5 \mathrm{Al}$ TWIP steel. tested at an initial strain rate of $2 \times 10^{-3} \mathrm{~s}^{-1}$. Two tensile specimens were used to obtain each experimental point. The fracture surfaces after tensile tests were observed using Quanta 200 3D scanning electron microscope.

\section{Results}

\subsection{Microstructure evolution}

Hot rolling and annealing resulted in the development of a uniform microstructure (Fig. 1) with an average grain size of $24 \mu \mathrm{m}$ containing numerous annealing twins and an average dislocation density of $\rho=10^{14} \mathrm{~m}^{-2}$.

At a reduction of $20 \%$, the initial grains elongated along the rolling direction and deformation twinning occurred in some favorably oriented grains (Fig. 2a). Relatively fine initial grains promoted mechanical twinning [5] and hindered the formation of a low-energy dislocation structure in the form of planar dislocation boundaries [32]. To elucidate the characteristics of the longitudinal features observed in Fig. 2a, EBSD analysis was performed on the $20 \%$ cold-rolled material. On one hand, grains with low misorientation angles across these longitudinal features indicate intragranular slip lines (grain 2 in Fig. 3). On the other hand, grains including a high number of $60^{\circ}$ misorientation angles along the misorientation line profile prove the presence of twin bundles containing $\Sigma 3$ grain boundaries $\left(60^{\circ}\{111\}\right)$, as exemplarily shown by the profile of grain 1 in Fig. 3. With respect to the operation of deformation twinning, three types of grains can be distinguished (Fig. 2a). Type I grains are almost free of mechanical twins. Type II grains contain one active primary twinning system. In these grains, the bundles of straight and thin twins alternate with the non-twinned matrix, and band-like regions of extensive mechanical twinning aligned with $\{111\}$ plane were observed (Fig. 4a). Type III grains were characterized by more than one primary twinning system or secondary twinning system. Most of the grains were of types I or II, whereas the fraction of type III grains was minor. In the type II and III grains, the average twin thickness was
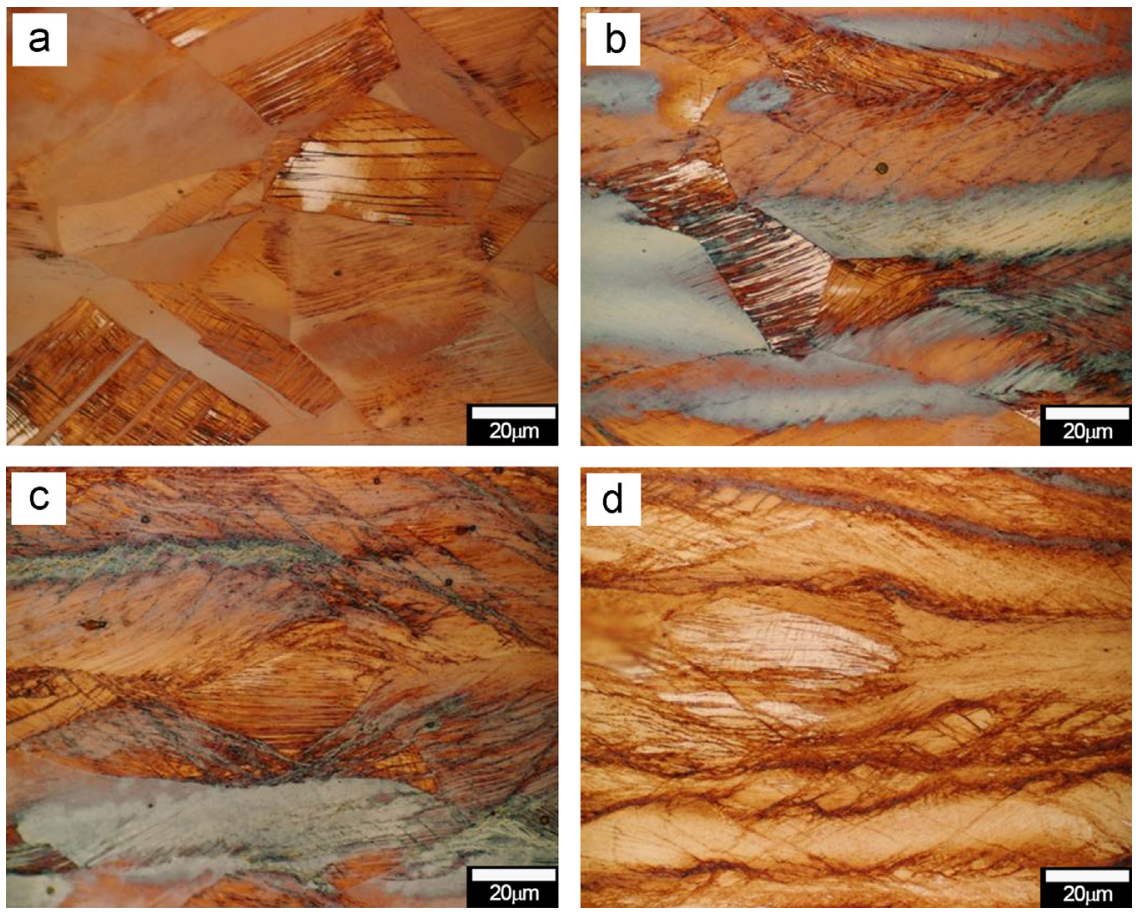

Fig. 2. Optical micrographs showing the microstructure of specimens after cold rolling: (a) $20 \%$, (b) $40 \%$, (c) $60 \%$ and (d) $80 \%$. 

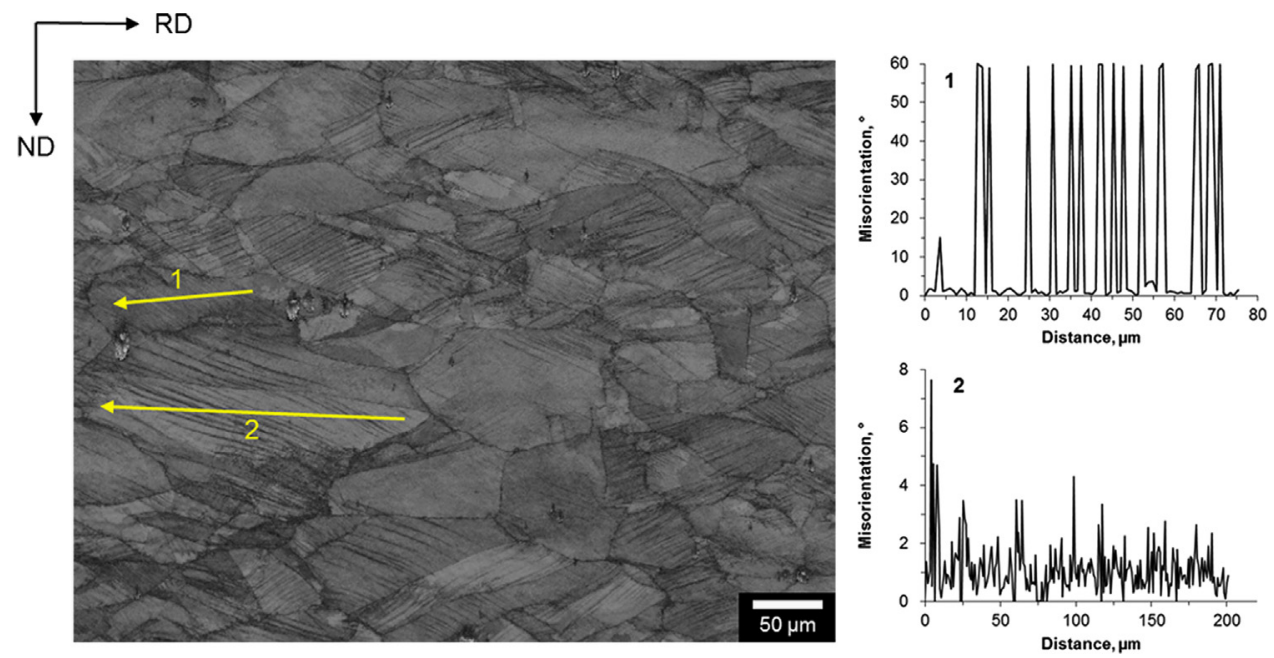

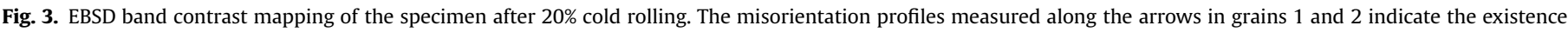
and absence of intragranular grain boundaries with a misorientation of $60^{\circ}$, i.e., twin boundaries.

approximately $20 \mathrm{~nm}$, and the average distance between the twins was $\sim 570 \mathrm{~nm}$. The dislocation density at a $20 \%$ rolling degree increased substantially to approximately $2 \times 10^{15} \mathrm{~m}^{-2}$ (Fig. 5), providing high internal stress.

As the rolling degree increases from 20 to $40 \%$, the number of deformation twins increased considerably (Figs. 2b, 4b), while the dislocation density remained nearly unchanged (Fig. 5). Almost all grains experienced deformation twinning. Therefore, the deformation microstructure consisted of type II and III grains. The bundles of deformation twins became thicker due to the increased number of twins within these bundles (Fig. 4b). Deformation twins belonging to several twinning systems appeared in many grains (Fig. 2b). The secondary twins crossed over the previous twins. An example of multiple twining with twins oriented along (15) and $(11 \overline{1})$ planes is presented in Fig. $4 \mathrm{~b}$. Up to three activated twinning systems were observed, with primary twinning systems being dominant. The angle between the primary and secondary twin planes, as depicted in Fig. $4 \mathrm{~b}$, is approximately $75^{\circ}$, which is close to the angle of $70.5^{\circ}$ between the $\{111\}$ twinning planes in an fcc lattice. In the type III grains, the multiple deformation twinning resulted in the subdivision of the non-twinned matrix into rectangular crystallites due to transverse deformation twins and dislocation boundaries (Figs. $2 \mathrm{~b}$ and $4 \mathrm{~b}$ ). In the type II grains, the mechanical twinning led to the development of nanoscale layered structures because of the small spacing between twin boundaries. Furthermore, the first micro shear bands with a typical angle of $40^{\circ}$ with the rolling direction were observed (Fig. $2 \mathrm{~b}$ ).

Further rolling to $60 \%$ reduction increased the density of twins and lattice dislocations concurrently (Figs. 2c, 4c, 5). It is worth noting that there were still many type II grains, in which only primary twin families could be observed. These twins also have orientation parallel to a $\{111\}$ plane. A specific feature of the microstructural evolution is that the previously formed twin boundaries tended to rearrange along rolling direction and thus promoted the appearance of micro shear bands to accommodate further strain (Fig. 2c). The micro shear bands sheared the previous deformation twins at acute angles below about $30^{\circ}$ as illustrated by Fig. 4c, where the micro shear band aligned along $(\overline{1} 1 \overline{3})$ crystal plane. This corresponds to other studies reported that micro shear bands in FCC crystals form as noncrystallographic band-like deformation regions of highly concentrated plastic flow $[33,34]$. The dislocation density at $60 \%$ rolling degree increased to $\rho \sim 3.5 \times 10^{15} \mathrm{~m}^{-2}$. Upon further processing to $80 \%$ rolling reduction, the number of shear bands and their thickness increased significantly (Figs. 2d, 4d and 5). The mutual intersection of shear bands and twins led to the formation of a spatial net of shear bands consisting of greatly misoriented crystallites with a size of $\sim 40 \mathrm{~nm}$. The evolution of nanocrystalline bands was accompanied by a further increase of the dislocation density to approximately $4.5 \times 10^{15} \mathrm{~m}^{-2}$

Fig. 5 summarizes the effect of cold rolling on the distance between deformation twins, twin thickness, dislocation density and volume fraction of shear bands. The dislocation density rapidly attained a high value of $2 \times 10^{15} \mathrm{~m}^{-2}$ just after $20 \%$ rolling reduction. The dislocation density then gradually increased with straining and approached $4.5 \times 10^{15} \mathrm{~m}^{-2}$ at the highest rolling reduction of $80 \%$. The deformation twins appeared with a thickness of $20 \mathrm{~nm}$, which remained almost constant during cold rolling. In general, this thickness is a characteristic feature of the primary twins. The thickness of the secondary twins was found to be less than $10 \mathrm{~nm}$.

However, an increase in the strain suppressed the secondary mechanical twinning; as a result, the overall twin thickness was mostly attributed to the thickness of the primary twins. On the other hand, the distance between twins decreased rapidly from $570 \mathrm{~nm}$ to $180 \mathrm{~nm}$ as the rolling reduction increased from $20 \%$ to $40 \%$, followed by a continuous decrease to $\sim 40 \mathrm{~nm}$ as the subsequent rolling reached $80 \%$. It should be noted that the decrease in the distance between the twins from $180 \mathrm{~nm}$ at a rolling reduction of $40 \%$ to $100 \mathrm{~nm}$ and $40 \mathrm{~nm}$ after rolling to $60 \%$ and $80 \%$, respectively, roughly corresponds to the overall change in the sample thickness. Thus, almost no new twins developed during rolling with reductions above $40 \%$. Therefore, extensive deformation twinning readily developed during rolling with reductions up to approximately $40 \%$. After that deformation twinning as a deformation mechanism seemed to be exhausted. This saturation of deformation twinning led to the development of shear banding at large rolling reductions. The volume fraction of shear bands increased from $\sim 7 \%$ to $21 \%$ with increasing rolling reduction from $60 \%$ to $80 \%$. Hence, the crystallites composing the shear bands may contribute to grain boundary strengthening in combination with the lamellas outlined by the twin boundaries [14].

\subsection{Mechanical properties}

The true stress-true strain curves and the change in the workhardening rate with true strain are presented in Fig. 6. No serrated flow attributed to DSA was found; thus, this phenomenon is not important for the mechanical behavior of the Fe-23Mn-0.3C-1.5Al 

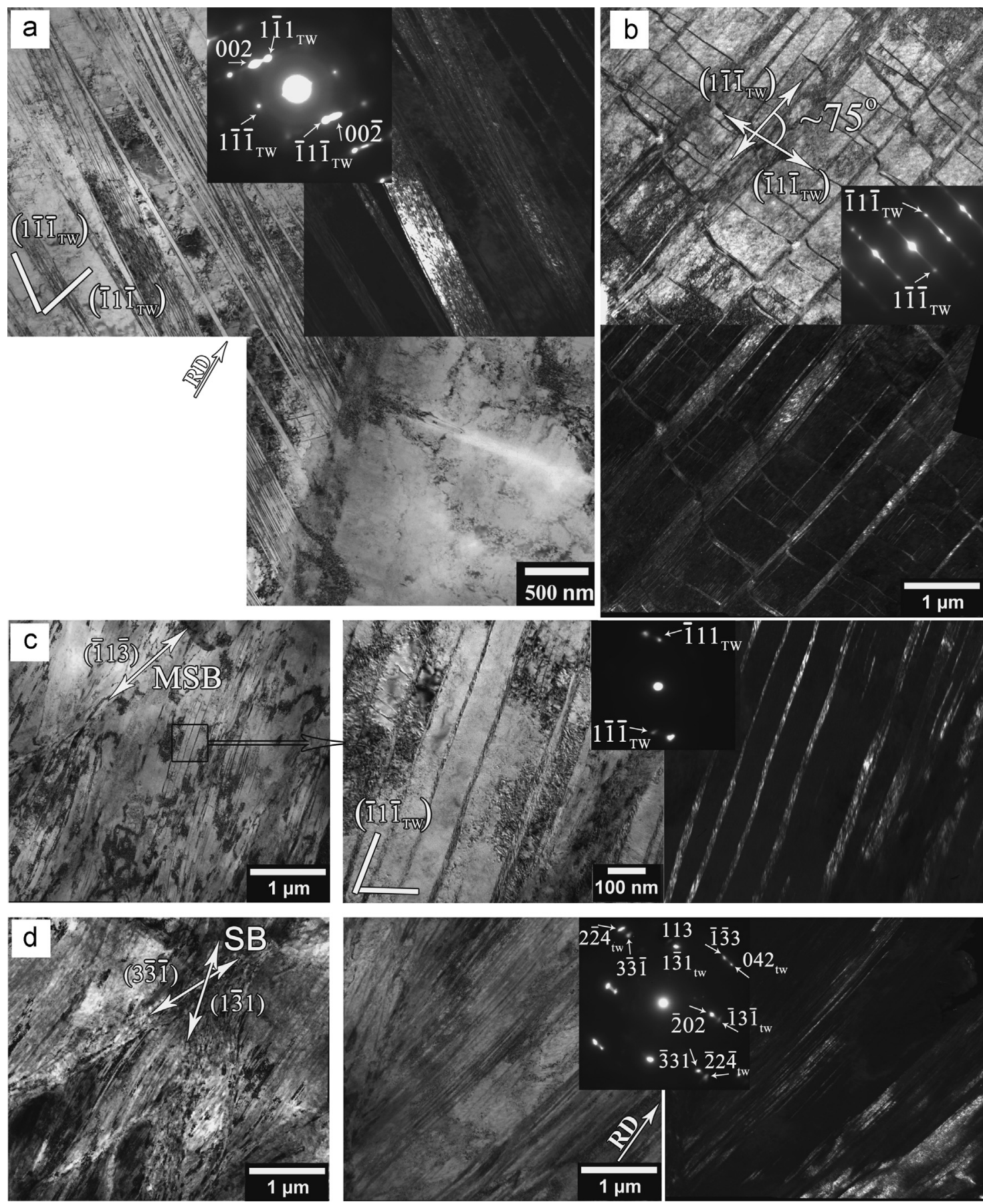

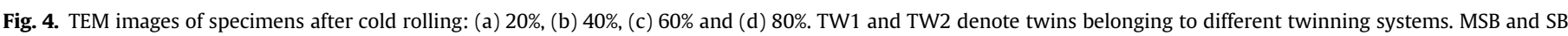
denote micro shear and shear bands, respectively.

steel. This steel exhibited a relatively low YS of $235 \mathrm{MPa}$ in the initial recrystallized state (Fig. 6a). Extensive strain hardening initially occurred at a rate of $\sim 1750 \mathrm{MPa}$, after which the rate increased slightly to $\sim 2000 \mathrm{MPa}$ during tension, providing exceptionally high necking resistance (Fig. 6b). As a result, a superior ductility of $96 \%$ was attained. It is worth noting that these values of elongation-to-failure and the strain-hardening rate are typical for Al-containing TWIP steels [2,24]. No well-defined yielding point could be found (Fig. 6a). This is in contrast to the data reported by Kim et al. [24] and may be attributed to the relatively coarse initial grain size [35].

The cold rolling with reductions of $20,40,60,80 \%$ provided increases of 193, 138, 427 and 495\% in the YS and 26, 48, 60 and
$66 \%$ in the UTS, respectively (Table 2). After a $20 \%$ rolling reduction, the UTS/YS ratio decreased from 2.81 in the initial state to 1.22 , and the ductility decreased by a factor of $\sim 3$. The rate of initial strain hardening decreased slightly to $\sim 1500 \mathrm{MPa}$ and tended to decrease gradually with strain to a value of $\sim 1150 \mathrm{MPa}$ at the end of the plastic stability stage. An increase in the rolling reduction led to a significant drop in the UTS/YS ratio down to $\sim 1.12$. The $\sigma-\varepsilon$ curves show a quite small uniform elongation followed by strain-softening to failure (Fig. 6). An apparent steady-state flow could be observed in the samples subjected to cold rolling with reductions below approximately $40 \%$ (Fig. 6). In the samples rolled with reductions above $40 \%$, the onset of localized necking occurred at peak stress, and the flow 

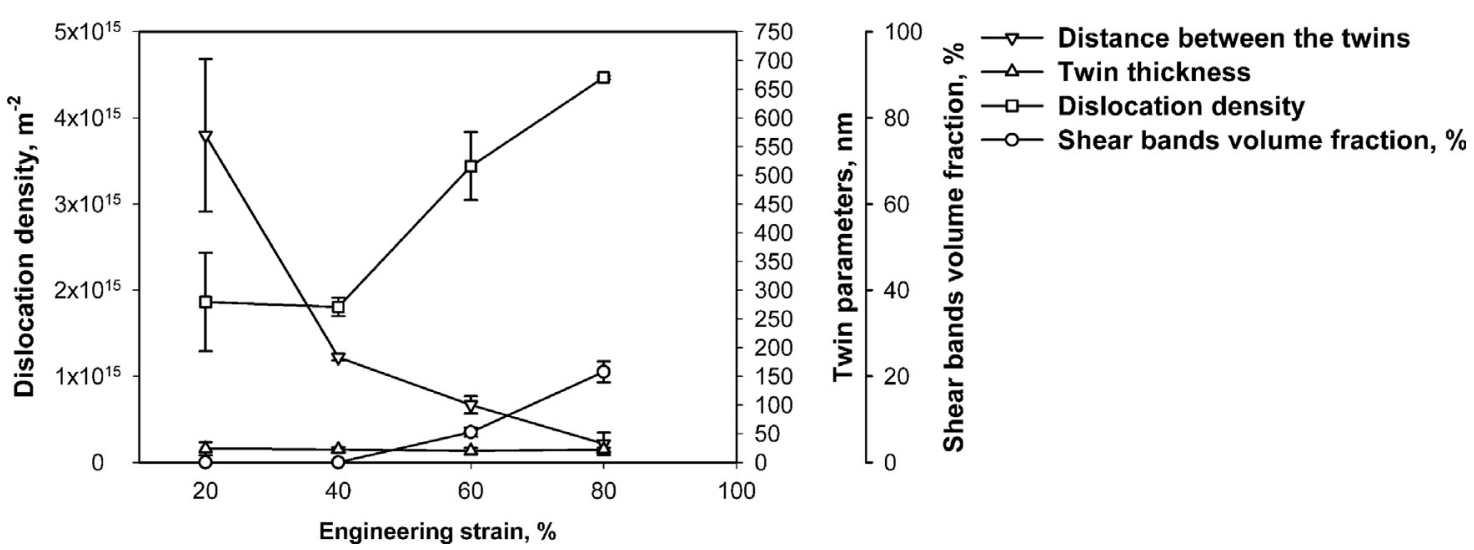

Fig. 5. Effect of cold rolling on the distance between the twins, twin thickness, shear band volume fraction and dislocation density in Fe-23Mn-0.3C-1.5Al steel.

a

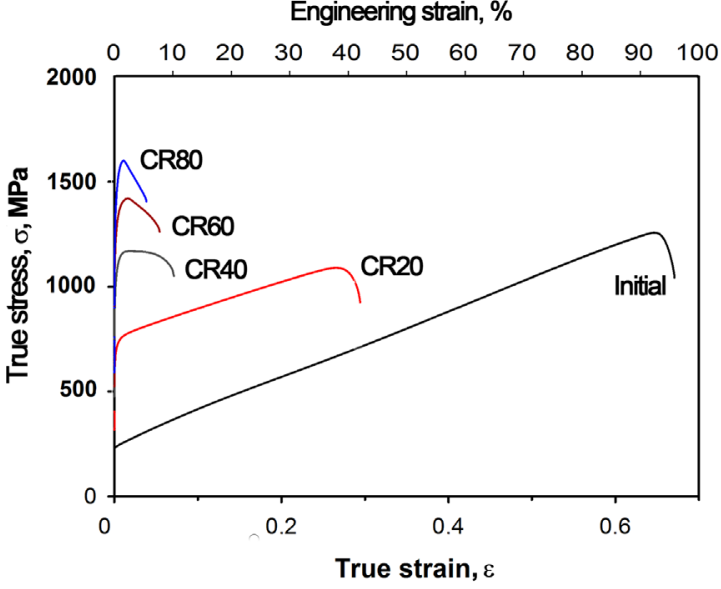

b

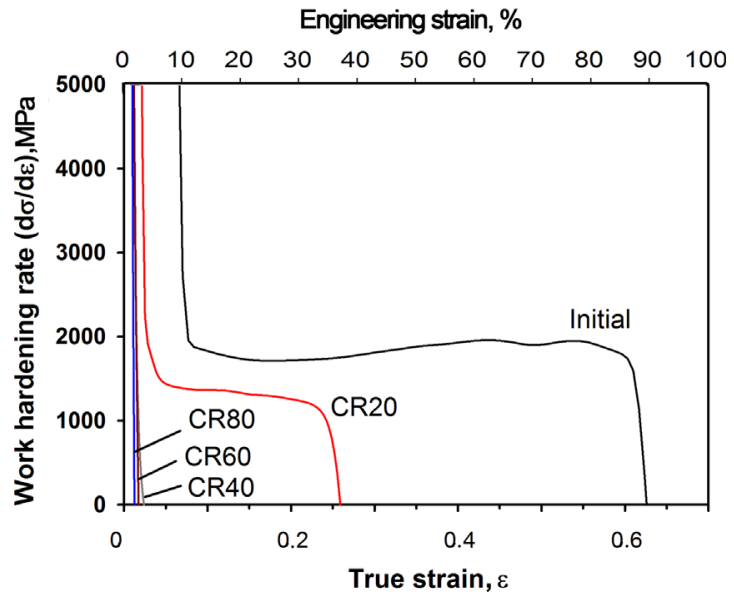

Fig. 6. (a) The stress-strain curves of Fe-23Mn-0.3C-1.5Al steel and (b) the work-hardening rate.

Table 2

Mechanical properties of Fe-23Mn-0.3C-1.5Al steel subjected to cold rolling. Deformed specimens are denoted as CRx, where CR means "cold rolled" and $\mathrm{x}$ indicates the reduction degree in $\%$.

\begin{tabular}{llrrrl}
\hline Specimen & $\begin{array}{l}\text { Rolling } \\
\text { strain }\end{array}$ & $\sigma_{0.2}, \mathrm{MPa}$ & $\sigma_{b}, \mathrm{MPa}$ & $\begin{array}{l}\text { Total } \\
\text { elongation, } \%\end{array}$ & $\begin{array}{l}\text { True strain to } \\
\text { failure, } \varepsilon\end{array}$ \\
\hline Initial & 0 & $235 \pm 10$ & $660 \pm 15$ & $96 \pm 2$ & $0.67 \pm 0.01$ \\
CR20 & 0.22 & $690 \pm 25$ & $840 \pm 24$ & $34.2 \pm 1.6$ & $0.29 \pm 0.016$ \\
CR40 & 0.51 & $1030 \pm 17$ & $1150 \pm 15$ & $7.3 \pm 0.4$ & $0.07 \pm 0.004$ \\
CR60 & 0.91 & $1240 \pm 25$ & $1400 \pm 20$ & $5.5 \pm 0.3$ & $0.05 \pm 0.003$ \\
CR80 & 1.61 & $1400 \pm 20$ & $1580 \pm 21$ & $3.9 \pm 0.3$ & $0.04 \pm 0.003$ \\
\hline
\end{tabular}

stress continuously decreased until fracture (Fig. 6). The uniform elongation decreased from $\varepsilon \sim 0.25$ at a rolling reduction of $20 \%$ to $\varepsilon \approx 0.02$ upon subsequent rolling with reductions above $40 \%$. As a result, the ductility decreased to $4-7 \%$ (Table 2 ). The critical rolling reduction for such a drastic change in the tensile behavior seemed to be approximately $40 \%$. The change in the tensile behavior was clearly correlated with the appearance of micro shear bands in the deformation microstructures. The early onset of necking and poor ductility were related to the disappearance of the strain-hardening stage due to the presence of a high dislocation density and extensive reduction of the effective grain size [35].

\subsection{Fractography}

The fracture surfaces of the initial and cold rolled samples subjected to tensile tests are shown in Fig. 7. A dimple rupture is the main fracture mechanism in all material conditions. Increasing rolling reduction leads to slow transition from transgranular to intergranular fracture path. It is apparent that the formation of shear bands and the intersection of twins belonging to different families promote microcrack initiation [36]. As a result, the size of the dimples decreases and the distribution of dimple dimensions becomes more uniform with increasing rolling reduction (Fig. 7). However, even at rolling reduction of $80 \%$, the transgranular fracture is dominant and intergranular fracture is an accompanying process (Fig. 7e). In the initial material the equiaxed dimples are deep and exhibit conical shape (Fig. 7a and b). At rolling reduction of $60 \%$ and higher, the shallow dimples appear (Fig. $7 \mathrm{~d}$ and e) that is indicative for limited plasticity, which can be experienced by largely rolled material. This conclusion is supported by the observation of cleavage in vicinity of microcracks, which appear parallel to the rolling direction (Fig. 7f). Since the main structural components, i.e., twins and shear bands, were aligned with rolling plane at large rolling reductions, the microcracks in largely rolled sample follow the arrangement of these structural components. Thus, mechanical twinning affects the fracture mode of the TWIP steel.

\section{Discussion}

The relationship between the microstructural evolution during cold rolling and the strength of Fe-23Mn-0.3C-1.5Al steel will be considered based on two strengthening mechanisms contributing to the overall strength: (i) grain boundary strengthening related 

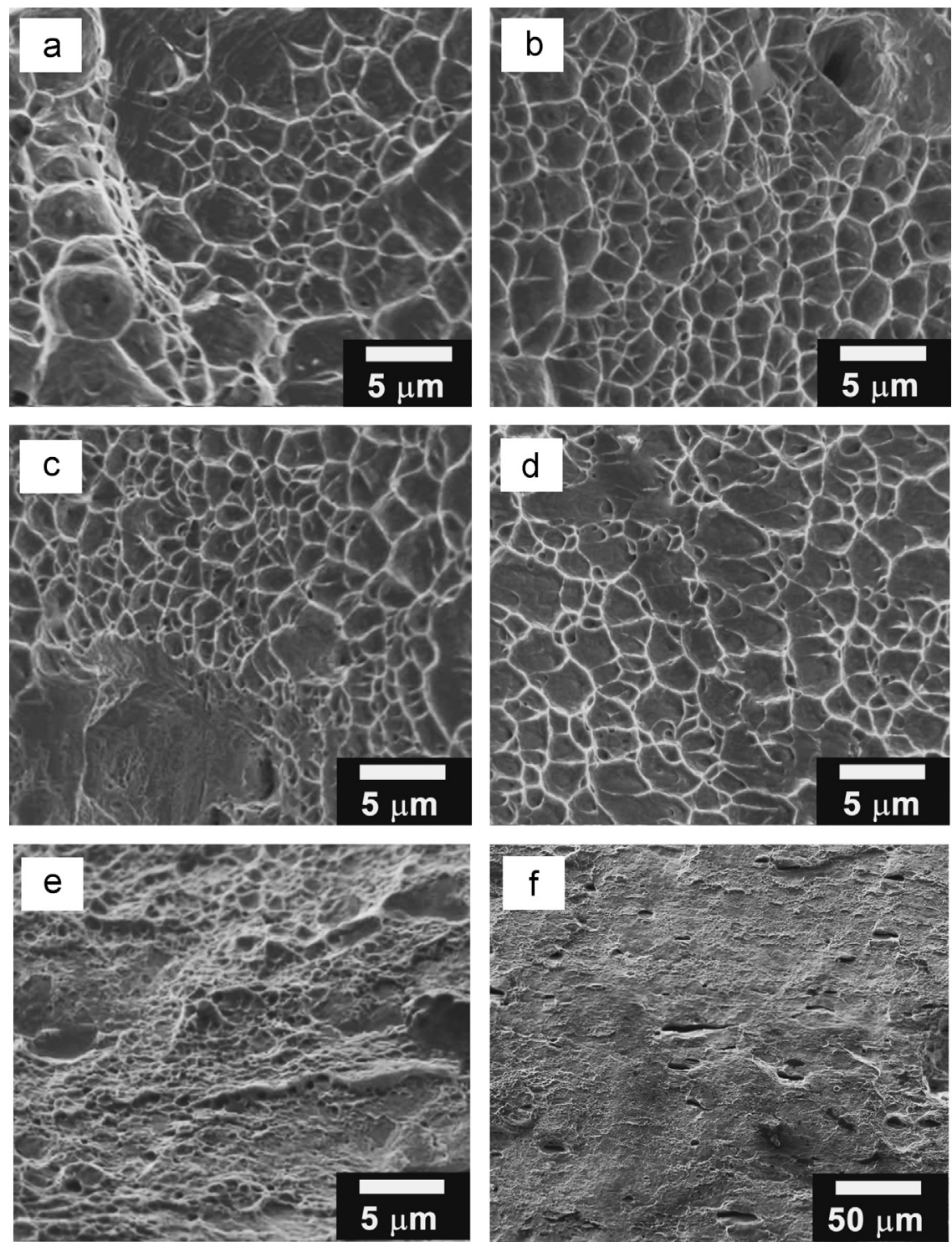

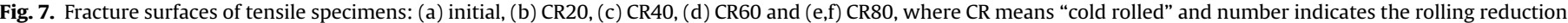
degree in \%.

to the thickness of the inter-twin lamellae and the size of the crystallites bounded by high-angle boundaries, which are impenetrable obstacles for gliding dislocations, and (ii) dislocation strengthening related to the very high dislocation density. As mentioned above, the solid solution hardening related to the DSA can be ignored.

\subsection{Deformation microstructures and mechanical behavior}

A schematic illustration of the deformation microstructures evolved during rolling is presented in Fig. 8. In general, there are two stages of microstructure evolution, which are clearly distinguished by analyzing the deformation microstructures. At rolling reductions below $40 \%$, the microstructure consists of elongated grains with a high dislocation density. These grains may be subdivided by mechanical twins. Despite this distinct difference between separate grains, the steel exhibits superior ductility, which assumes no localization of plastic deformation within some grains. Therefore, there is no difference in the plastic deformation between grains of different types. This may be attributed to the fact that the subdivision of initial grains by deformation twins has a minor effect on flow stress. It seems that all types of initial grains are able to sustain plastic flow by operation of dislocation sources and that increasing stress during tension mainly results from increased dislocation density.

At rolling reductions above $40 \%$, three types of structural components evolve (Fig. 8): type II and type III grains and a nanocrystalline structure within areas of localized shear. A distinct change in the tensile behavior (Fig. 6) and the microstructural evolution (Figs. 2 and 4 ) takes place at a rolling reduction of $\sim 40 \%$, when the feasibility of deformation twinning to accommodate plastic flow terminates. Further rolling results in increased dislocation density and subdivision of initial grains to nanoscale crystallites, which leads to a significant increase in the internal elastic strain. Therefore, at rolling reduction higher than $40 \%$, the steel loses the ability to maintain further plastic flow by simple emission of new dislocations. As a result, the material experienced difficulty in propagating the plastic flow through different microstructural components to provide general yielding of the specimen under tension condition. Accordingly, very high stress is required 


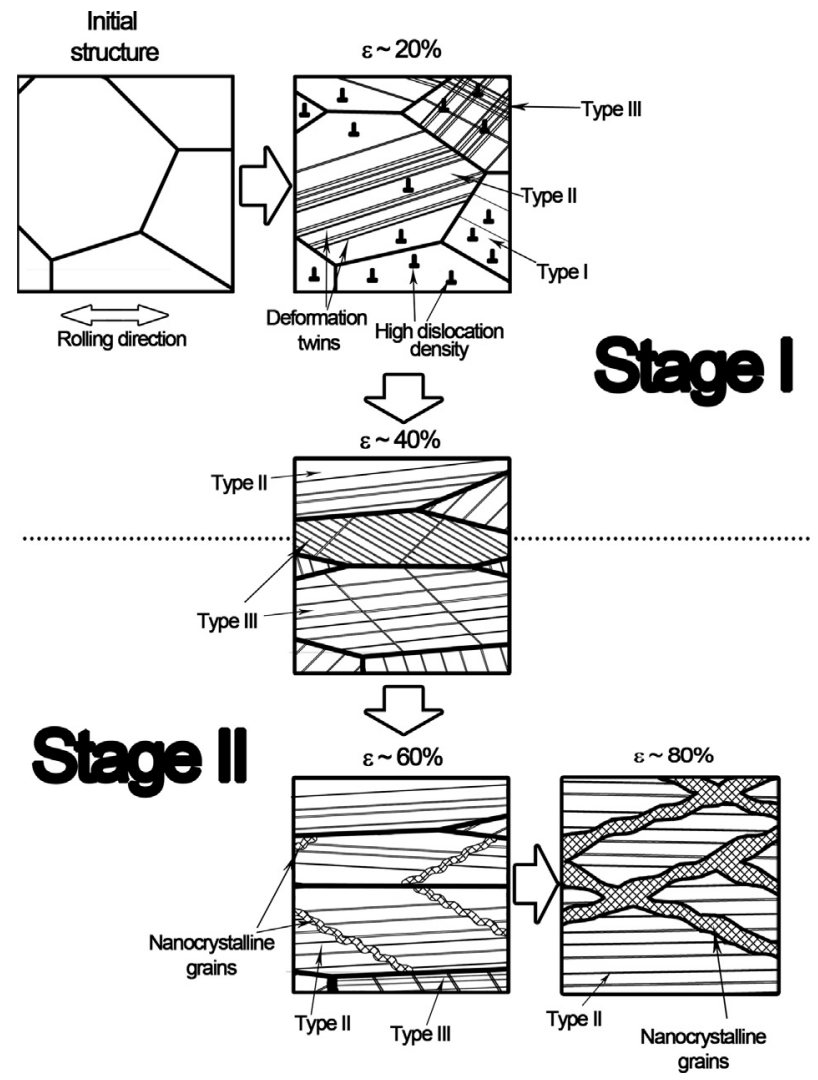

Fig. 8. Schematic representation of the evolution of deformation structures during rolling.

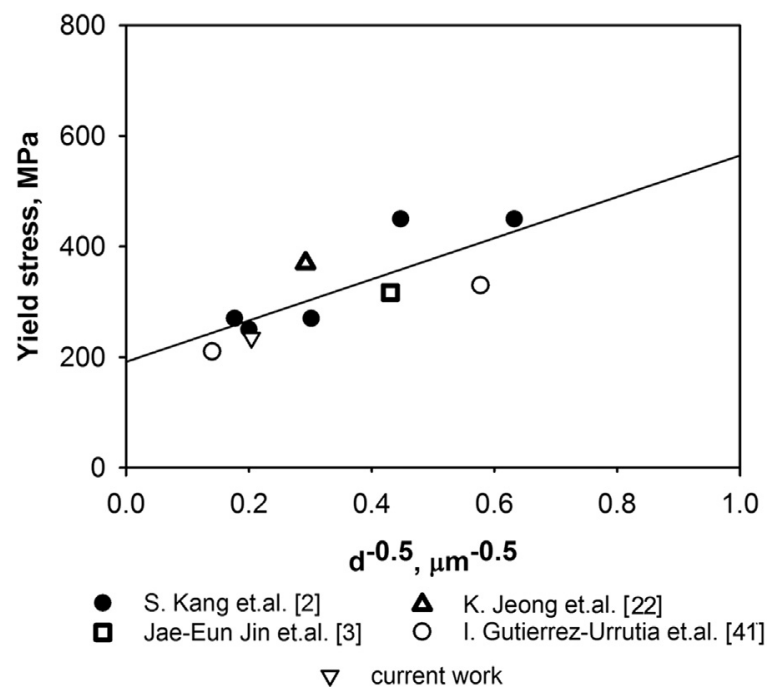

Fig. 9. The Hall-Petch relation obtained for various high-Mn TWIP steels.

to initiate plastic flow; and stress localization within structural components with lower yielding leads to premature fracture due to unstable plastic flow.

\subsection{Quantitative analysis of the strain hardening}

Fig. 9 shows the effect of grain size on the YS observed for the present and other high-Mn TWIP steels $[2,3,39]$. The strengthening is well represented by a Hall-Petch type relationship (Eq. (1)) with the friction stress of $\sigma_{0} \sim 200 \mathrm{MPa}$ and the Hall-Petch coefficient of $K_{H}=0.35 \mathrm{MPa} \mathrm{m}^{0.5}$. These values are very close to the friction stress and the Hall-Petch coefficient reported for $\mathrm{Cr}-\mathrm{Ni}$ austenitic steels, in which extensive grain refinement was achieved through intense plastic straining and/or the reversion from deformation-induced martensite into austenite and therefore contain a high dislocation density [37]. Thus, the investigated Fe$23 \mathrm{Mn}-0.3 \mathrm{C}-1.5 \mathrm{Al}$ steel exhibits a typical grain boundary strengthening, as also observed for other austenitic steels.

It is worth noting that the estimation of the effect of grain size on YS in austenitic steel with a dislocation density higher than $\rho \sim 10^{14} \mathrm{~m}^{-2}$ without considering the contribution of the deformation strengthening overestimates the $K_{H}$ value [10,37]. An analysis of the deformation strengthening mechanism in addition to grain boundary strengthening can be achieved using the modified Hall-Petch equation [10,14]:

$\mathrm{YS}=\sigma_{0}+\alpha M G b \sqrt{ } \rho+K d^{-0.5}$

where $\alpha$ is a constant, $M=3$ is the average Taylor factor and $G=72000 \mathrm{MPa}$ is the shear modulus. The effective grain size $d$ was calculated as the grain size for type I grains or twice the distance between twin boundaries for type II and III grains. After rather large rolling reductions the present steel is characterized by the development of shear bands consisting of nanoscale crystallites, which should also be taken into account when considering the relationship between YS and microstructure. This can be achieved by including an additional term in the modified Hall-Petch equation, as follows:

$\mathrm{YS}=\sigma_{0}+\alpha M G b \sqrt{ } \rho+K\left((1-f) d^{-0.5}+f d_{\mathrm{SB}}^{-0.5}\right)$

where $f$ is the volume fraction of the shear bands and $d_{\mathrm{SB}}$ is the size of the nanoscale crystallites within the shear bands. The best fit of the experimental results was obtained with $\alpha=0.21$ and $K=0.11 \mathrm{MPa} \mathrm{m}^{0.5}$. The obtained grain size strengthening factor $K$ in Eq. (6) is approximately a third of $K_{H}$ in Eq. (1). However, the $K=0.11 \mathrm{MPa} \mathrm{m}^{0.5}$ is equal to the value obtained for an austenitic steel containing a high dislocation density when a similar separation of the contributions of boundary strengthening and dislocation strengthening has been made [10]. Thereby, the YS can be expressed as

$\mathrm{YS}=\left[200+11 \sqrt{ } \rho+0.11\left((1-f) d^{-0.5}+f d_{\mathrm{SB}}^{-0.5}\right)\right] \mathrm{MPa}$

Eq. (7) suggests that the twin boundaries play an important role as strong obstacles for dislocation glide in TWIP steels and that the formation of twin boundaries contributes to the grain size strengthening in the same way as the formation of conventional

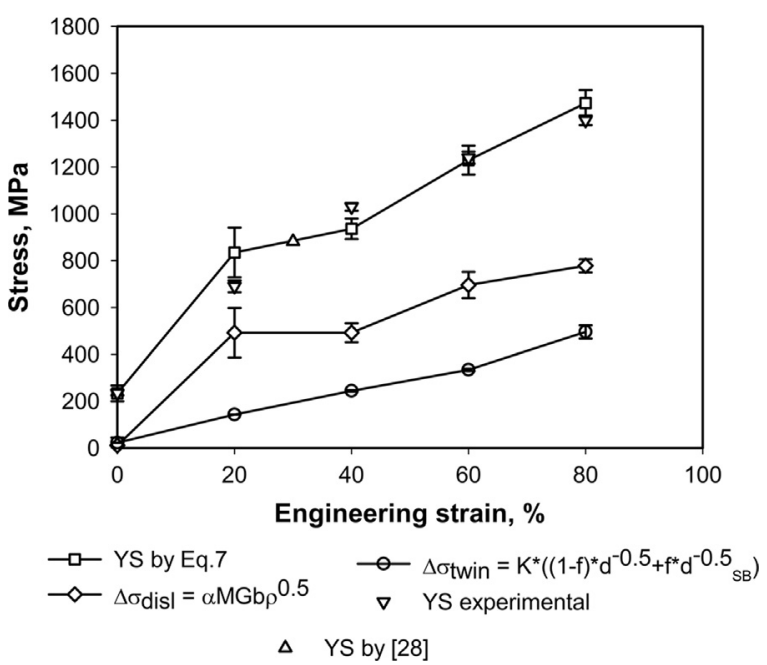

Fig. 10. Experimental and calculated values of the yield stress of the investigated Fe-23Mn-0.3C-1.5Al steel specimens subjected to different rolling strains. 
high-angle boundaries. Thus, the mechanical twinning can be considered a mechanism of extensive grain refinement from the viewpoint of the effective grain size.

Fig. 10 summarizes the relationship between the rolling strain and the YS as calculated by Eq. (7) as well as the contributions of the grain size strengthening and the dislocation strengthening to the overall YS. It is observed that the deformation strengthening provides the main contribution to the YS. The strengthening effect from twin boundaries is much smaller, although the contribution of boundary strengthening increases with increasing rolling reduction. The grain boundary strengthening contributed approximately 0.2 and 0.6 of the dislocation strengthening after cold rolling with $20 \%$ and $80 \%$ reductions, respectively. Therefore, the superior strain-hardening rate of the TWIP steels is attributed to the feasibility of a 20 -fold increase in the dislocation density to above $2 \times 10^{15} \mathrm{~m}^{-2}$ during deformation to true strains of $\sim 0.5$, which can be attained under tension conditions. It should be emphasized that such high dislocation densities can be attained in conventional metallic materials by severe plastic deformation to large total strains, which are not attainable in tensile tests. Thus, the extensive mechanical twinning greatly facilitates the storage of lattice dislocations [38]. This role of twinning is key to providing the extraordinary combination of strength and ductility.

\section{Summary}

The deformation microstructures and mechanical properties of Fe-23Mn-0.3C-1.5Al TWIP steel subjected to cold rolling were studied. The obtained results can be summarized as follows.

1. The microstructure of the steel after $20 \%$ cold rolling was characterized by high dislocation density and numerous deformation twins within the initial grains. The density of the deformation twins increased with increasing rolling reduction followed by an exhaustion of the deformation twinning at a rolling reduction of $40 \%$. Correspondingly, the distance between twins rapidly decreased to $\sim 200 \mathrm{~nm}$ upon a rolling reduction of $40 \%$ and then gradually decreased to $\sim 40 \mathrm{~nm}$ after an $80 \%$ rolling reduction due to the macroscopic reduction of the sheet thickness. In contrast, the twin thickness of $\sim 20 \mathrm{~nm}$ did not depend on the rolling reduction.

2. Cold rolling with reductions above approximately $40 \%$ led to the development of shear bands. The deformation microstructure that evolved after $80 \%$ rolling reduction was composed of twinned crystallites separated by shear bands, which consisted of largely misoriented nanoscale crystallites with a size of approximately $40 \mathrm{~nm}$.

3. The yield stress increased from $690 \mathrm{MPa}$ to $1400 \mathrm{MPa}$ with increasing rolling reduction from 20 to $80 \%$. The increment in the ultimate tensile strength was nearly the same, whereas the elongation to failure decreased from $36 \%$ to $4 \%$.

4. The dimple fracture plays a major role in rupture of tensile specimens irrespective of previous rolling reduction. Increasing rolling reduction leads to decreasing the dimple size and transition from conically shaped dimples to shallow dimples. After rolling reduction of $80 \%$ the microcracks aligned with rolling plane appear.

5. The yield stress (YS) of the investigated steel can be expressed as $\mathrm{YS}=\left[200+11 \sqrt{ } \rho+0.11\left((1-f) d^{-0.5}+f d_{\mathrm{SB}}^{-0.5}\right)\right] \mathrm{MPa}$, where $\rho$ is the dislocation density, $f$ is the volume fraction of the shear bands and $d$ and $d_{\mathrm{SB}}$ are the effective grain size (double spacing between twin boundaries) and the size of nanocrystallites within shear bands, respectively.
6. Dislocation strengthening provided a significantly greater contribution to the yield stress than grain boundary strengthening. Grain boundary strengthening contributed approximately 0.2 and 0.6 of the dislocation strengthening after cold rolling with $20 \%$ and $80 \%$ reductions, respectively.

\section{Acknowledgments}

The financial support received from the Department of Internal and Personnel policies of the Belgorod region, Russia, (Belgorod State University project no. G-17) is gratefully acknowledged. Two of the authors ( $\mathrm{CH}$ and $\mathrm{DM}$ ) express their gratitude to the Deutsche Forschungsgemeinschaft (DFG) for financial support within the Collaborative Research Centre (SFB) program 761: "Steel - ab initio; quantum mechanics guided design of new $\mathrm{Fe}$ based materials". The authors are grateful to the personnel of the Joint Research Centre, Belgorod State University, for their assistance with instrumental analysis.

\section{References}

[1] H. Hofmann, D. Mattissen, T.W. Schaumann, Steel Res. Int. 80 (2009) 22-28.

[2] K. Jeong, J.-E. Jin, Y.-S. Jung, S. Kang, Y.-K. Lee, Acta Mater. 61 (2013) 3399-3410.

[3] J.-E. Jin, Y.-K. Lee, Mater. Sci. Eng. A 527 (2009) 157-161.

[4] H.K. Yang, Z.J. Zhang, Z.F. Zhang, Scr. Mater. 68 (2013) 992-995.

[5] I. Gutierrez-Urrutia, D. Raabe, Acta Mater. 59 (2011) 6449-6462.

[6] H. Idrissi, K. Renard, D. Schryvers, P.J. Jacques, Scr. Mater. 63 (2010) 961-964.

[7] J.W. Christian, S. Mahajan, Progr. Mater. Sci 39 (1995) 1-157.

[8] H. Idrissi, K. Renard, L. Ryelandt, D. Schryvers, P.J. Jacques, Acta Mater. 58 (2010) 2464-2476.

[9] J.G. Sevillano, Scr. Mater. 60 (2009) 336-339.

[10] Z. Yanushkevich, A. Mogucheva, M. Tikhonova, A. Belyakov, R. Kaibyshev, Mater. Charact. 62 (2011) 432-437.

[11] E.O. Hall, Proc. Phys. Soc. B 64 (1951) 747-753.

[12] N.J. Petch, J. Iron Steel Inst. 174 (1953) 25-28.

[13] M. Kato, Mater. Trans. 55 (2014) 19-24.

[14] X. Zhang, A. Godfrey, X. Huang, N. Hansen, Q. Liu, Acta Mater. 59 (2011) 3422-3430.

[15] O. Bouaziz, Scr. Mater. 66 (2012) 982-985.

[16] B. Hutchinson, N. Ridley, Scr. Mater. 55 (2006) 299-302.

[17] S.-J. Lee, J. Kim, Sh. N. Kane, B. Ch. De Cooman, Acta Mater. 59 (2011) 6809-6819.

[18] V. Bata, E.V. Pereloma, Acta Mater. 52 (2004) 657-665.

[19] R.Z. Valiev, Mater. Trans. 55 (2014) 13-18.

[20] C.E. Carlton, P.J. Ferreira, Acta Mater. 55 (2007) 3749-3756.

[21] T.G. Nieh, J. Wadsworth, Scr. Metall. Mater. 25 (1991) 955-958.

[22] I. Gutierrez-Urrutia, D. Raabe, Acta Mater. 60 (2012) 5791-5802.

[23] D.R. Steinmetz, T. Japel, B. Wietbrock, Ph. Eisenlohr, I. Gutierrez-Urrutia, A. Saeed-Akbari, T. Hickel, F. Roters, D. Raabe, Acta Mater. 61 (2013) 494-510.

[24] J. Kim, Y. Estrin, B.C. De Cooman, Metall. Mater. Trans. 44 A (2013) 4168-4182.

[25] O. Bouaziz, S. Allain, C.P. Scott, P. Cugya, D. Barbier, Curr. Opin. Solid State Mater. Sci. 15 (2011) 141-168.

[26] C. Haase, L.A. Barrales-Mora, D.A. Molodov, G. Gottstein, Metall. Mater. Trans, A 44 (2013) 4445-4459.

[27] Y.P. Lü, D.A. Molodov, G. Gottstein, ISIJ Int. 51 (2011) 812-817.

[28] C. Haase, S.G. Chowdhury, L.A. Barrales-Mora, D.A. Molodov, G. Gottstein, Metall. Mater. Trans. A 44 (2013) 911-922.

[29] G.K. Williamson, W.H. Hall, Acta Metall. 1 (1953) 22-31.

[30] B.E. Warren, J. Biscoe, J. Am. Ceram. Soc. 21 (1938) 49-54.

[31] R.E. Smallman, K.H. Westmacott, Philos. Mag. 2 (1957) 669-683.

[32] G. Winther, D. Juul Jensen, N. Hansen, Acta Mater. 45 (1997) 5059-5068.

[33] N. Jia, P. Eisenlohr, F. Roters, D. Raabe, X. Zhao, Acta Mater. 60 (2012) 3415-3434.

[34] H. Paul, J.H. Driver, C. Maurice, Z. Jasiennski, Mater. Sci. Eng. A 359 (2003) $178-191$.

[35] C.Y. Yu, P.W. Kao, C.P. Chang, Acta Mater. 53 (2005) 4019-4028.

[36] Y.-J. Dai, D. Tang, Z.-L. Mi, J.-C. Lu, Int. J. Iron .Steel Res. 17 (2010) 53-59.

[37] Ya. Shakhova, V. Dudko, A. Belyakov, K. Tsuzaki, R. Kaibyshev, Mater. Sci. Eng. A 545 (2012) 176-186.

[38] L. Chen, Han-Soo Kim, Sung-Kyu Kim, B.C. De-Cooman, ISIJ Int. 47 (2007) 1804-1812.

[39] I. Gutierrez-Urrutia, S. Zaefferer, D. Raabe, Mater. Sci. Eng. A 527 (2010) $3552-3560$. 